\title{
IDENTIFICAÇÃO DE MANIFESTAÇÕES PATOLÓGICAS EM MARQUISES DE EDIFICAÇÕES NA CIDADE DE CASCAVEL/PR
}

\author{
ANTONIAZZI COUSSIAN, JULIA \\ Estudante \\ Unioeste \\ Paraná; Brasil \\ julia.a.coussian@gmail.com
}

\author{
WISSMANN, JORGE A. \\ Professor universitário \\ Unioeste \\ Paraná; Brasil \\ jorge.wissmann@unioeste.br
}

\author{
DE SOUSA SANTANA DE OLIVEIRA, ANA MARIA \\ Professora universitária \\ Unioeste \\ Paraná; Brasil \\ asantanadeoliveira@gmail.com
}

\section{RESUMO}

As estruturas de concreto armado são projetadas para determinado intervalo de tempo, chamado de vida útil. A interação da estrutura com a agressividade do ambiente, assim como as falhas decorrentes da fase de projeto, execução e/ou uso, vem a ocasionar o surgimento de manifestações patológicas. $\mathrm{O}$ agravamento destas, em consequência da falta de manutenção, provoca deterioração da estrutura, podendo levá-la ao colapso. Tal situação toma maior proporção quando se trata de marquises, que são elementos construtivos que se projetam sobre o logradouro público, onde há circulação de transeuntes. O significativo aumento no número de acidentes envolvendo marquises, muitos resultando em vítimas fatais, leva a preocupação quanto à segurança estrutural deste elemento, haja vista sua única vinculação com o restante da estrutura e seu comportamento de ruptura frágil. Na presente pesquisa, realizou-se inspeção visual em 10 marquises da região central da cidade de Cascavel/PR, com objetivo de identificar as manifestações patológicas presentes e apresentouse a incidência destas. Ainda, utilizou-se da metodologia GDE/UnB para avaliar o grau de deterioração das marquises inspecionadas, de modo a quantificar seu nível de degradação e o grau de risco que oferecem. Os resultados obtidos mostraram que algumas marquises necessitam de intervenção imediata, de modo a se evitar a ocorrência de acidentes. Observou-se ainda que estas marquises passam por pouca ou nenhuma manutenção, fator que possibilita ainda mais o comprometimento estrutural destas, pela evolução dos processos de deterioração.

Palavras-chave: marquises, manifestações patológicas, deterioração, vistoria.

\section{ABSTRACT}

Reinforced concrete structures are designed for a specified period of time, called the service life. The interaction of the structure with the environment and faults during the design development, execution and/or phase of use, causes the emergence of pathological manifestations. The aggravation of these, as a result of lack of maintenance, will cause structure deterioration which can lead to collapse. This situation takes bader proportions when talking about cantilever slabs, which are constructive elements that project itself over the public place, where there is circulation of passers-by. The significant increase number of accidents involving cantilever slabs, many resulting in fatal victims, leads to a concern with the structural safety of this element, considering its single link with the rest of the structure and its rupture behavior. In the present research, a visual inspection was performed in 10 cantilever slab of the central region of Cascavel/PR, aiming to identify pathological manifestations and its incidences. Also, the GDE / UnB methodology was used to evaluate the deterioration degree of the cantilever slabs inspected, in order to quantify their degradation level and risks. The obtained results shows that some cantilever slabs demands immediately intervation, in order to avoid the occurrence of accidents. Also note that these cantilever slab undergo little or no maintenance, situation that colaborates with structural insecurity, through the evolution of the deterioration processes.

Keywords: cantilever slab, pathological manifestations, deterioration, inspection. 


\section{INTRODUÇÃO}

No início do século XX no Brasil, com a implementação do uso do cimento Portland e desenvolvimento de métodos de dimensionamento do concreto armado, foi possível a evolução de técnicas construtivas, que por sua vez resultaram em um processo de verticalização das construções (RIZZO, 2007). A partir de então, com o crescente incremento da altura das edificações nos grandes centros urbanos, surgiu a preocupação acerca dos perigos que a queda de objetos poderia trazer aos transeuntes (RIZZO, 2007). Neste contexto, surgem as marquises como elemento construtivo.

De acordo com Oliveira (2013), as marquises são estruturas constituídas por laje em balanço, a qual projeta-se sobre o logradouro público e é vinculada à estrutura através de um único engaste. Sendo assim, este torna-se o ponto crítico da estrutura, visto que a falha desse elemento pode ocasionar a ruína da mesma, que geralmente ocorre de forma frágil, ou seja, sem aviso. Em função destas peculiaridades, torna-se imprescindível minimizar e controlar a presença das manifestações patológicas nestas estruturas.

O primeiro documento que regulamentou a construção de marquises foi o Decreto 6000/1.937 do Estado do Rio de Janeiro, no qual tornou-se obrigatória a execução de marquises, principalmente em centros comerciais e em outras edificações, dependendo do zoneamento (RIZZO, 2007). Posteriormente, esta medida foi também adotada em São Paulo e outras capitais brasileiras.

Atualmente, embora dispensada a obrigatoriedade de construção de marquises, estas continuam a ser construídas, tornando-se parte da cultura da construção de edifícios (NAKAGUMA, 2006). Para além da proteção contra quedas de objetos, as marquises também fornecem proteção aos raios solares e chuva, podendo também apresentar variadas formas com caráter estético (OLIVEIRA, 2013).

Entretanto, o significativo número de ocorrências de acidentes levantou a preocupação quanto à estabilidade e segurança destas estruturas, surgindo novas legislações referentes ao uso de marquises, com foco na manutenção preventiva e periódica das mesmas. As causas mais frequentes de acidentes envolvendo marquises, de acordo com Medeiros e Grochoski (2007), são a corrosão de armaduras, a sobrecarga na estrutura, os erros de projeto, o mau uso da edificação, as falhas na execução e a infiltração de água.

O ponto crítico das marquises é a armadura superior, pois esta é a primeira a ser afetada quando a impermeabilização falha ou quando surgem trincas de qualquer natureza na parte superior da estrutura (DORIGO, 1996 apud CARMO, 2009). Uma vez que é iniciada a corrosão das barras de aço, estas sofrem redução de seção, e ocorre formação de compostos expansivos que levam ao surgimento de fissuras e trincas. Estas por sua vez, facilitam a entrada de outros agentes agressivos, dando continuidade ao ciclo (PERUCK; ZANCAN; 2011).

A prevenção da ocorrência de manifestações patológicas em marquises inicia-se na fase do projeto, com o correto dimensionamento dos elementos estruturais, e especificação de cobrimento mínimo de concreto para a armadura (NAKAGUMA, 2006). Ainda de acordo com o mesmo autor, na sequência deve-se ter os cuidados com a execução, os quais contemplam o posicionamento correto das armaduras e colocação de espaçadores, a fim de garantir o cobrimento especificado. Além disso, é importante projeto de impermeabilização e correto dimensionamento e manutenção dos sistemas coletores de águas pluviais.

Durante a fase de uso da estrutura, a inspeção predial torna-se de extrema importância, pois, de acordo com Medeiros e Grochoski (2007), a maioria das causas de acidentes envolvendo marquises são passíveis de serem evitadas por um programa de inspeção e manutenção periódica. Não sendo possível a instauração de uma correta estratégia de manutenção e limpeza, devem-se ser colocados em prática métodos de reforço e recuperação da estrutura (PINTO; MONTE; 2015).

Diante do exposto, esta pesquisa teve como objetivo identificar (por meio de inspeções visuais) as manifestações patológicas presentes em marquises da região central do município de Cascavel/PR, apresentar a incidência destas manifestações e classificar as marquises quanto ao seu grau de deterioração.

\section{METODOLOGIA}

Para a realização da pesquisa, fez-se uma inspeção visual preliminar na área central do município de Cascavel/PR, buscando-se identificar os casos mais críticos, para os quais se buscou autorização junto ao proprietário do imóvel, para se realizar inspeção detalhada. Deste modo, obteve-se uma amostra de 10 marquises. 
Para cada marquise em que se obteve autorização para a inspeção detalhada, foi realizada uma caracterização da mesma, mediante uma entrevista preliminar com o proprietário ou responsável pela edificação, com o objetivo de identificar as principais características e se obter um histórico da edificação. O modelo de questionário direcionado ao proprietário é apresentado na Tabela 1.

Tabela 1 - Entrevista com o proprietário (Fonte: Adaptado de Ribeiro, 2014)

\begin{tabular}{l|c}
\hline Função do Entrevistado: & Lojista/proprietário/síndico \\
\hline Endereço: & Rua, número \\
\hline Edifício: & Nome do Edifício \\
\hline Idade do imóvel: & "X" anos \\
\hline Uso/ocupação atual: & Uso/ocupação \\
\hline Uso/ocupações anteriores: & Uso/ocupação \\
\hline Posse de projeto estrutural: & SIM/NÃO \\
\hline Existência de manutenção: & SIM/NÃO \\
\hline Frequência: & "X" vezes/ano \\
\hline Tipo: & Impermeabilização, estrutural, estética \\
\hline
\end{tabular}

Após a caracterização das marquises, foi realizada inspeção visual detalhada em cada uma delas. Para isto, contou-se com o auxílio de uma escada, para visualizar a região superior das marquises, câmera fotográfica e trena para realizar medições.

Para identificação das manifestações patológicas, contou-se com o auxílio de um checklist, elaborado pela autora, mediante adaptações dos checklists de Gonçalves (2011) e Gomes et al (2003).

\subsection{Método para determinação do grau de deterioração de estruturas - Metodologia GDE/UnB}

Para se avaliar o grau de deterioração das marquises em estudo, utilizou-se da metodologia GDE/UnB - Grau de deterioração da estrutura/Universidade de Brasília, a qual foi elaborada por Castro (1994) com o objetivo de quantificar o grau de deterioração de estruturas de concreto armado convencionais.

Esta metodologia permite avaliar quantitativamente o grau de deterioração de um elemento isolado ou da estrutura como um todo, baseando-se em parâmetros que consideram as manifestações mais frequentes de danos, sua evolução e a influência do meio ambiente no qual a estrutura está inserida (CASTRO, 1994).

A metodologia consiste na divisão da estrutura em famílias de elementos estruturais típicos. Para estruturas usuais de concreto armado, podem ser definidas as seguintes famílias: pilares, vigas, lajes, cortinas, escadas e rampas, reservatório superior e inferior, blocos, juntas de dilatação e elementos de composição arquitetônica. Para cada elemento da família, lista-se as possíveis manifestações de danos com seu respectivo fator de ponderação de dano e fator de intensidade de dano.

O fator de ponderação de dano visa quantificar a importância relativa de um determinado dano em relação às condições gerais de estética, funcionalidade e segurança do elemento. Um determinado dano pode ter diferentes fatores de ponderação, dependendo das características da família onde o elemento em análise se insere e das consequências que o mesmo pode acarretar. Tal fator deve variar em uma escala de 0 a 5, de acordo de acordo com reformulação realizada por Fonseca (2007), a qual modificou a escala de 0 a 10, inicialmente proposta por Castro (1994).

$\mathrm{Na}$ presente pesquisa, os danos avaliados nas marquises e seus respectivos fatores de ponderação ( $\left.\mathrm{F}_{\mathrm{p}}\right)$ são apresentados na Tabela 2.

Tabela 2 - Fatores de ponderação para inspeção de marquises (Fonte: Adaptado de Gonçalves, 2011)

\begin{tabular}{l|c}
\hline Danos & $\mathbf{F}_{\mathbf{p}}$ \\
\hline Armaduras expostas com corrosão & 5 \\
\hline Desagregação & 3 \\
\hline Desplacamento & 3 \\
\hline Eflorescência & 2 \\
\hline Falhas de concretagem & 3 \\
\hline
\end{tabular}




\begin{tabular}{l|c}
\hline Danos & $\mathbf{F}_{\mathbf{p}}$ \\
\hline Fissuras & 3 a $5^{\mathbf{1}}$ \\
\hline Flechas & 5 \\
\hline Ataque biológico & 3 \\
\hline Umidade & 3 \\
\hline Desvio de geometria & 3 \\
\hline
\end{tabular}

${ }^{1}$ Valor variável a depender da direção da fissura

O fator de intensidade de dano $\left(\mathrm{F}_{\mathrm{i}}\right)$ visa classificar o nível de gravidade e a evolução da manifestação do dano. Tal fator varia em uma escala de 0 a 4, e é atribuído de acordo com a avaliação subjetiva do vistoriador, considerando-se as classificações apresentadas na Tabela 3.

Tabela 3 - Fatores de intensidade de dano (Fonte: Castro, 1994)

\begin{tabular}{c|c}
\hline $\mathbf{F}_{\mathbf{i}}$ & Classificação \\
\hline 0 & Sem lesões \\
\hline 1 & Lesões leves \\
\hline 2 & Lesões toleráveis \\
\hline 3 & Lesões graves \\
\hline 4 & Estado Crítico \\
\hline
\end{tabular}

A partir dos fatores de ponderação e fatores de intensidade definidos para cada dano, calcula-se o parâmetro denominado Grau de Dano do elemento (D), o qual é obtido através das Equações 1 e 2, reformuladas por Fonseca (2007) em função da consideração da escala de 0 a 5 para o fator de ponderação de dano.

$$
\begin{aligned}
& \mathrm{D}=0,8 \mathrm{~F}_{\mathrm{i}} \mathrm{F}_{\mathrm{p}} \text { para } \mathrm{F}_{\mathrm{i}} \leq 2 \\
& \mathrm{D}=\left(12 \mathrm{~F}_{\mathrm{i}}-28\right) \mathrm{F}_{\mathrm{p}} \text { para } \mathrm{F}_{\mathrm{i}} \geq 3
\end{aligned}
$$

onde:

$\mathrm{F}_{\mathrm{i}}$ : Fator de intensidade do dano

$\mathrm{F}_{\mathrm{p}}$ : Fator de ponderação do dano

De posse do parâmetro Grau de Dano do elemento, pode-se calcular o Grau de Deterioração de um elemento $\left(\mathrm{G}_{\mathrm{de}}\right)$, a partir da Equação 3, proposta por Lopes (1998).

$$
\mathrm{G}_{\mathrm{de}}=\mathrm{D}_{\text {máx }}\left[1+\frac{\sum_{\mathrm{i}=1}^{\mathrm{m}} \mathrm{D}_{(\mathrm{i})}-\mathrm{D}_{\text {máx }}}{\sum_{\mathrm{i}=1}^{\mathrm{m}} \mathrm{D}_{\mathrm{i}}}\right]
$$

onde:

$\mathrm{G}_{\mathrm{de}}$ : Grau de deterioração de um elemento estrutural

$\mathrm{D}_{\text {máx }}$ : Maior grau de dano no elemento estrutural

m: Número de danos avaliados no elemento

$\mathrm{D}_{(\mathrm{i})}$ : Grau de dano de ordem (i).

Obtido o valor de grau de deterioração do elemento, classifica-se o elemento estrurual em relação ao seu grau de deterioração de acordo com a Tabela 4.

Tabela 4 - Classificação quanto ao grau de deterioração do elemento (Fonte: Fonseca, 2007)

\begin{tabular}{l|c}
\hline Nível de deterioração & $\mathbf{G}_{\mathbf{d e}}$ \\
\hline Baixo & $0-15$ \\
\hline Médio & $15-50$ \\
\hline Alto & $50-80$ \\
\hline Sofrível & $80-100$ \\
\hline Crítico & $>100$ \\
\hline
\end{tabular}


Na presente pesquisa, para as marquises formadas apenas por laje, a metodologia GDE/UnB apresentada, foi utilizada até o cálculo do grau de deterioração do elemento (Equação 3), haja vista que neste caso a laje é o único elemento constituinte da marquise.

Para os casos das marquises compostas por laje apoiada em vigas, fez-se necessário seguir todos os passos que compõem a metodologia. Assim sendo, calculou-se, separadamente, o grau de deterioração do elemento (Equação 3) para laje e para vigas e, definiu-se o fator de relevância estrutural $\left(\mathrm{F}_{\mathrm{r}}\right)$. Tal fator, segundo a metodologia, tem por objetivo demonstrar a importância relativa das diversas famílias de elementos no comportamento e desempenho da mesma. Adotou-se os valores de 4 e 5 para lajes e vigas, respectivamente, conforme apresentado na Tabela 5.

Tabela 5 - Fatores de relevância estrutural (Fonte: Fonseca, 2007)

\begin{tabular}{c|c}
\hline $\mathbf{F}_{\mathbf{r}}$ & Família de elementos \\
\hline 1,0 & Elementos de composição arquitetônica \\
\hline 2,0 & Reservatório superior \\
\hline 3,0 & Escadas/Rampas, Reservatório inferior, Cortinas, Lajes secundárias \\
\hline 4,0 & Lajes, fundações, vigas secundárias, pilares secundários \\
\hline 5,0 & Vigas e pilares principais \\
\hline
\end{tabular}

Na sequência, para se chegar ao grau de deterioração destas marquises, formadas por lajes e vigas, utilizou-se a Equação 4, e procedeu-se a sua classificação de acordo com a Tabela 4, apresentada anteriormente.

$$
\mathrm{G}_{\mathrm{d}}=\frac{\sum_{\mathrm{i}=1}^{\mathrm{K}} \mathrm{F}_{\mathrm{r}(\mathrm{i})} \mathrm{G}_{\mathrm{df}(\mathrm{i})}}{\sum_{\mathrm{i}=1}^{\mathrm{m}} \mathrm{F}_{\mathrm{r}(\mathrm{i})}}
$$

onde:

$\mathrm{G}_{\mathrm{d}}$ : Grau de deterioração global da estrutura

$\mathrm{F}_{\mathrm{r}_{(\mathrm{i})}}$ : Fator de relevância estrutural da família de elementos de ordem (i)

$\mathrm{G}_{\mathrm{df}(\mathrm{i})}$ : Grau de deterioração da família de elementos de ordem (i)

k: Número de famílias de elementos consideradas

\section{RESULTADOS E DISCUSSÕES}

\subsection{Caracterização das marquises}

Na Tabela 6, são apresentadas as características das marquises inspecionadas, com base nos dados obtidos durante as entrevistas com os proprietários, síndicos ou outros responsáveis pelas edificações, referentes ao uso e idade da edificação e existência, tipo e frequência da manutenção.

Para as marquises identificadas como M01, M04, M05, M06 e M08 não foi possível localizar o proprietário da edificação e as mesmas não apresentam síndico responsável. Deste modo, não foi possível obter informações relativas à manutenção destas marquises. Em relação à idade destas edificações, buscou-se registros através da prefeitura do município, não se obtendo êxito para a marquise M04.

Tabela 6 - Informações obtidas com a entrevista (Fonte: A autora, 2019)

\begin{tabular}{c|c|c|c|c|c}
\hline Identificação & $\begin{array}{c}\text { Uso/ocupação } \\
\text { da edificação }\end{array}$ & $\begin{array}{c}\text { Idade da } \\
\text { edificação }\end{array}$ & Manutenção & $\begin{array}{c}\text { Frequência } \\
\text { da manutenção }\end{array}$ & $\begin{array}{c}\text { Tipo de } \\
\text { manutenção }\end{array}$ \\
\hline M01 & $\begin{array}{c}\text { Comercial/ } \\
\text { Residencial }\end{array}$ & 48 anos & - & - & - \\
\hline M02 & Comercial & $\sim 50$ anos & Existente & Última há 6 anos & $\begin{array}{c}\text { Pintura e } \\
\text { Impermeabilização }\end{array}$ \\
\hline M03 & $\begin{array}{c}\text { Comercial/ } \\
\text { Residencial }\end{array}$ & $\sim 50$ anos & Existente & Última há 2 anos & Pintura \\
\hline M04 & $\begin{array}{c}\text { Comercial/ } \\
\text { Residencial }\end{array}$ & - & - & - & - \\
\hline
\end{tabular}




\begin{tabular}{c|c|c|c|c|c}
\hline Identificação & $\begin{array}{c}\text { Uso/ocupação } \\
\text { da edificação }\end{array}$ & $\begin{array}{c}\text { Idade da } \\
\text { edificação }\end{array}$ & Manutenção & $\begin{array}{c}\text { Frequência } \\
\text { da manutenção }\end{array}$ & $\begin{array}{c}\text { Tipo de } \\
\text { manutenção }\end{array}$ \\
\hline M06 & $\begin{array}{c}\text { Comercial/ } \\
\text { Residencial }\end{array}$ & 40 anos & - & - & - \\
\hline M07 & Comercial & $\sim 50$ anos & Existente & Última a 4 anos & Pintura \\
\hline M08 & $\begin{array}{c}\text { Comercial/ } \\
\text { Residencial }\end{array}$ & 50 anos & - & - & - \\
\hline M09 & $\begin{array}{c}\text { Comercial/ } \\
\text { Residencial }\end{array}$ & 43 anos & Existente & Última a 2 anos & Pintura \\
\hline M10 & Comercial & 34 anos & Existente & Última a 3 anos & Pintura \\
\hline
\end{tabular}

Caracterizou-se também as marquises em relação às suas características geométricas, tais quais como: arranjo estrutural, comprimento em balanço, altura em relação a via pública e espessura da laje. Tais resultados são apresentados na Tabela 7.

Tabela 7 - Características geométricas das marquises (Fonte: A autora, 2019)

\begin{tabular}{c|c|c|c|c}
\hline Identificação & Arranjo estrutural & $\begin{array}{c}\text { Comprimento } \\
\text { em balanço }\end{array}$ & $\begin{array}{c}\text { Altura em relação } \\
\text { a via pública }\end{array}$ & $\begin{array}{c}\text { Espessura } \\
\text { da laje }\end{array}$ \\
\hline M01 & $\begin{array}{c}\text { Laje apoiada em vigas engastadas } \\
\text { (invertidas) }\end{array}$ & $2 \mathrm{~m}$ & $3,20-3,9 \mathrm{~m}$ & $12 \mathrm{~cm}$ \\
\hline $\mathbf{M 0 2}$ & Laje engastada diretamente em laje & $1,05 \mathrm{~m}$ & $2,95-3,30 \mathrm{~m}$ & $16 \mathrm{~cm}$ \\
\hline $\mathbf{M 0 3}$ & Laje apoiada em vigas engastadas & $1 \mathrm{~m}$ & $2,80-3,60 \mathrm{~m}$ & $11 \mathrm{~cm}$ \\
\hline $\mathbf{M 0 4}$ & Laje engastada diretamente em laje & $1,30 \mathrm{~m}$ & $3,60 \mathrm{a} 4,00 \mathrm{~m}$ & $10 \mathrm{~cm}^{2}$ \\
\hline $\mathbf{M 0 5}$ & Laje engastada diretamente em viga & $1,05 \mathrm{~m}$ & $3,60 \mathrm{~m}$ & $8 \mathrm{~cm}^{3}$ \\
\hline M06 & Laje engastada diretamente em viga & 1,20 & $2,90 \mathrm{~m}$ & $14 \mathrm{~cm}$ \\
\hline M08 & Laje engastada diretamente em laje & $1 \mathrm{~m}$ & $4 \mathrm{~m}$ & $18 \mathrm{~cm}$ \\
\hline M09 & Laje engastada diretamente em laje & $1,52 \mathrm{~m}$ & $3,20 \mathrm{~m}$ & $13 \mathrm{~cm}$ \\
\hline L10 & Laje engastada diretamente em viga & $1,10 \mathrm{~m}$ & $3,20 \mathrm{~m}$ & $11 \mathrm{~cm}$ \\
\hline
\end{tabular}

${ }^{2}$ Laje com seção transversal variável

${ }^{3}$ Valor médio - laje com intensa degradação na extremidade do balanço

\subsection{Frequência das manifestações patológicas}

No gráfico da Figura 1, é apresentada a frequência dos principais problemas e manifestações patológicas encontrados em marquises. $\mathrm{O}$ intervalo de valores varia de 0 a 10 , conforme o número de marquises pesquisadas que apresentaram a patologia ou o problema indicado.

O primeiro item refere-se à deterioração da pintura, a qual foi observada nas marquises através da presença de descascamentos, bolhas e eflorescências. Embora todas as marquises tenham apresentado algum grau deste tipo de deterioração, este não se mostrou um fator preocupante em relação a segurança estrutural das mesmas, por se tratar de deteriorações superficiais, influenciando com maior intensidade na questão estética da edificação.

O segundo e terceiro itens do gráfico da Figura 1, referem-se à deterioração do revestimento argamassado (emboço e reboco) das marquises. Esta degradação foi observada através da presença de desplacamentos e desagregação de tais 
revestimentos, assim como, pela presença de fissuras e/ou trincas nos mesmos. Esta situação demonstra uma situação mais crítica à medida que permite a entrada de agentes agressivos para a superfície de concreto. A Figura 2 apresenta exemplos de situações encontradas com deterioração da pintura e deterioração do revestimento argamassado.

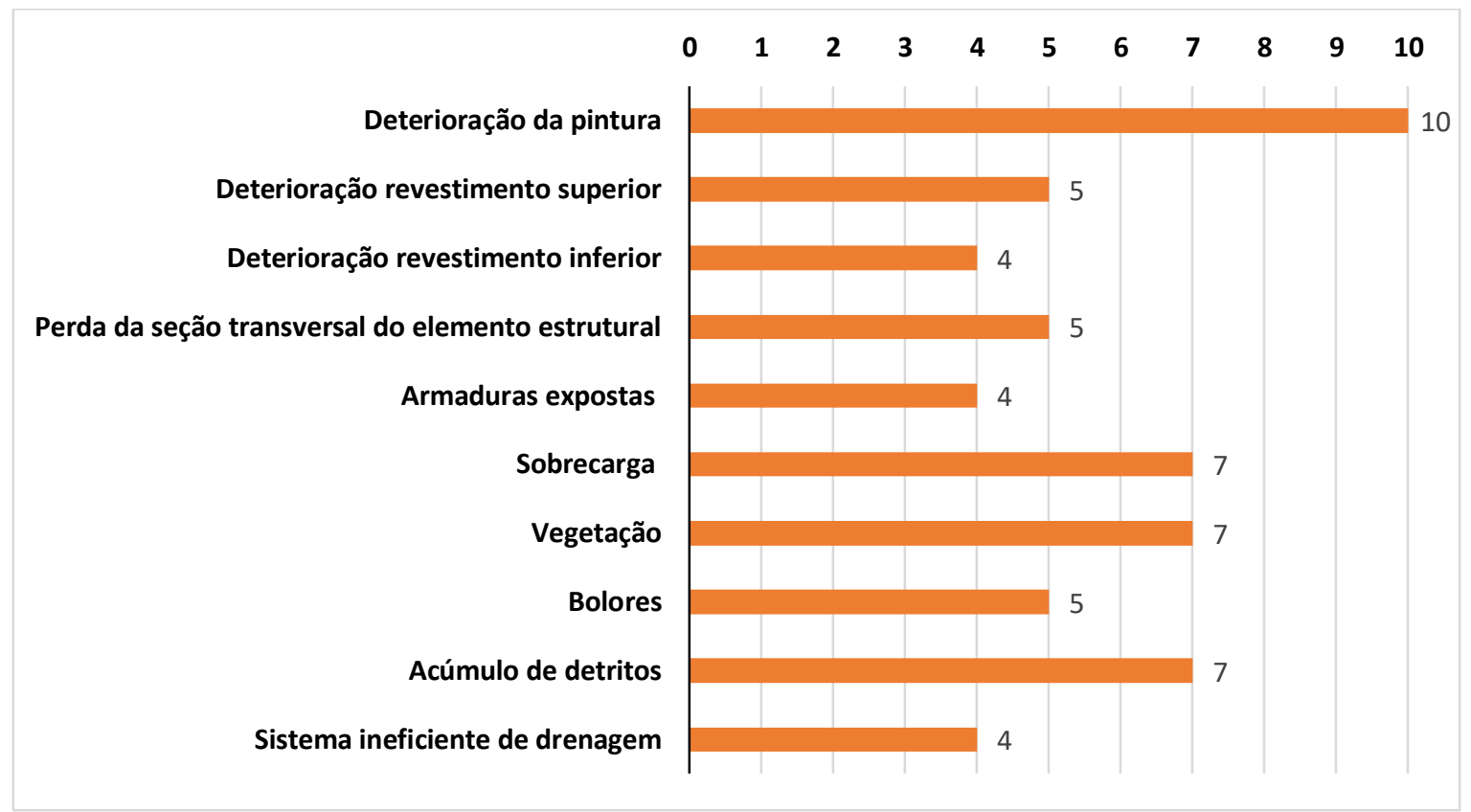

Figura 1: Frequência das manifestações patológicas (A autora, 2019)

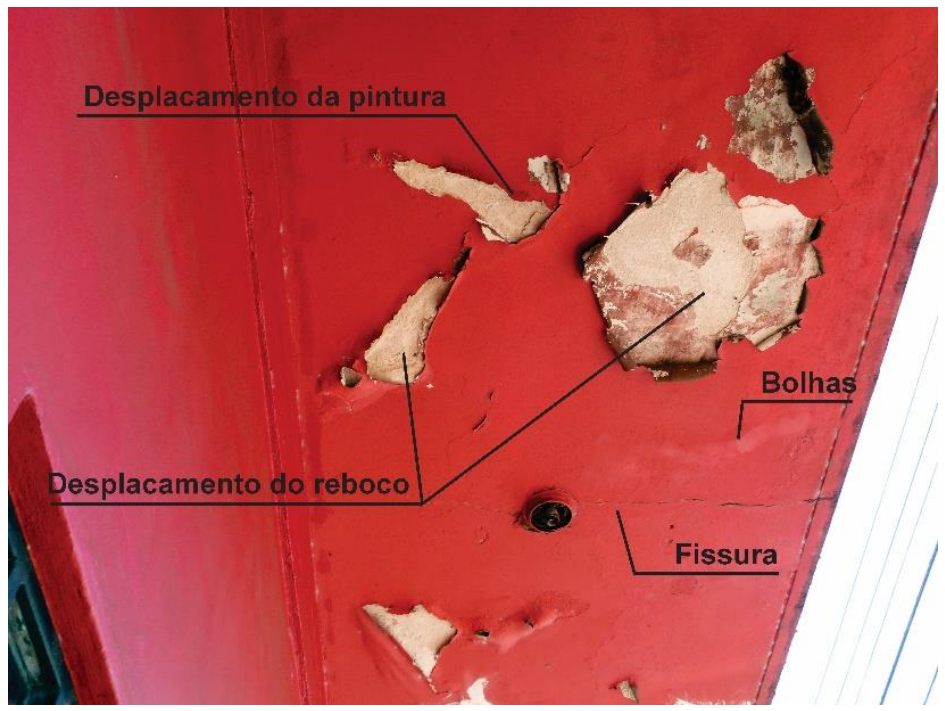

Figura 2: Região inferior da laje da marquise M04 (A autora, 2019)

O quarto item do referido gráfico, corresponde à perda da seção transversal do elemento estrutural, por meio de processos de desagregação e desplacamentos do concreto. A evolução destes processos conduz à exposição das armaduras (quinto item do gráfico da Figura 1) e consequente oxidação destas, representando, portanto, comprometimento da segurança estrutural do elemento. Os casos mais críticos desta situação foram encontrados nas marquises M01 e M03, conforme apresentado nas Figuras 3 e 4, respectivamente.

O sexto item apresentado no gráfico da Figura 1, refere-se a sobrecarga. Esta foi observada nas marquises pela presença de aparelhos de ar condicionado, antenas, estocagem de materiais e entulhos, vasos de plantas e letreiros comerciais. Tal situação pode ocasionar um processo de abertura de fissuras, em função do elemento estrutural ser solicitado com cargas maiores que as previstas em seu dimensionamento, e por consequência, provocar a evolução de outros problemas patológicos, ao permitir a entrada de agentes agressivos. As Figuras 5 e 6 apresentam alguns exemplos de sobrecarga encontrados. 


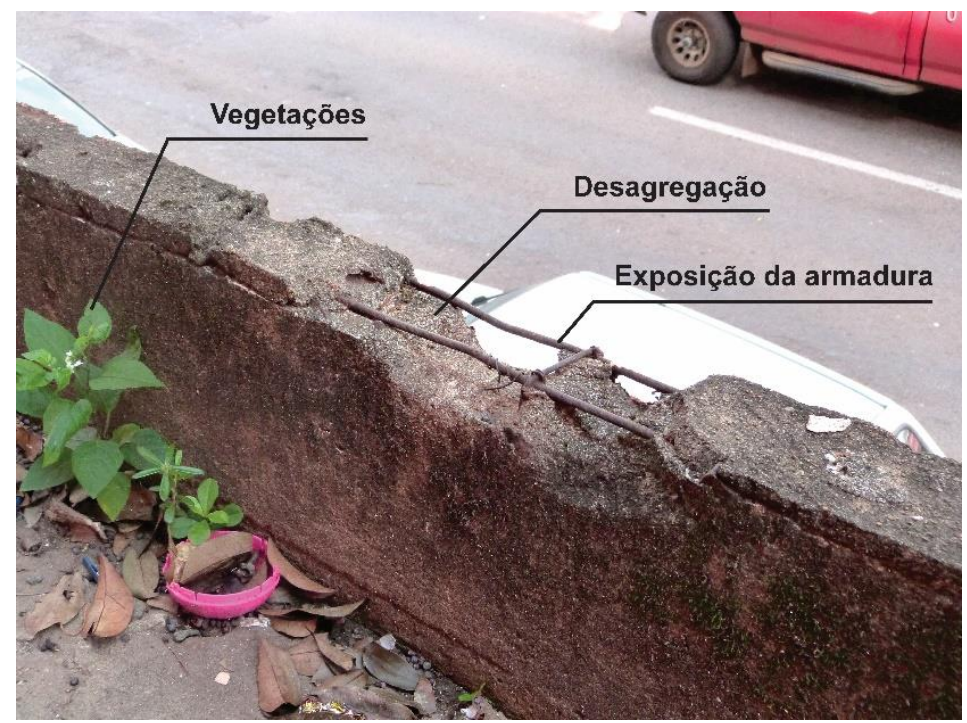

Figura 3: Viga de borda da marquise M01 (A autora, 2019)

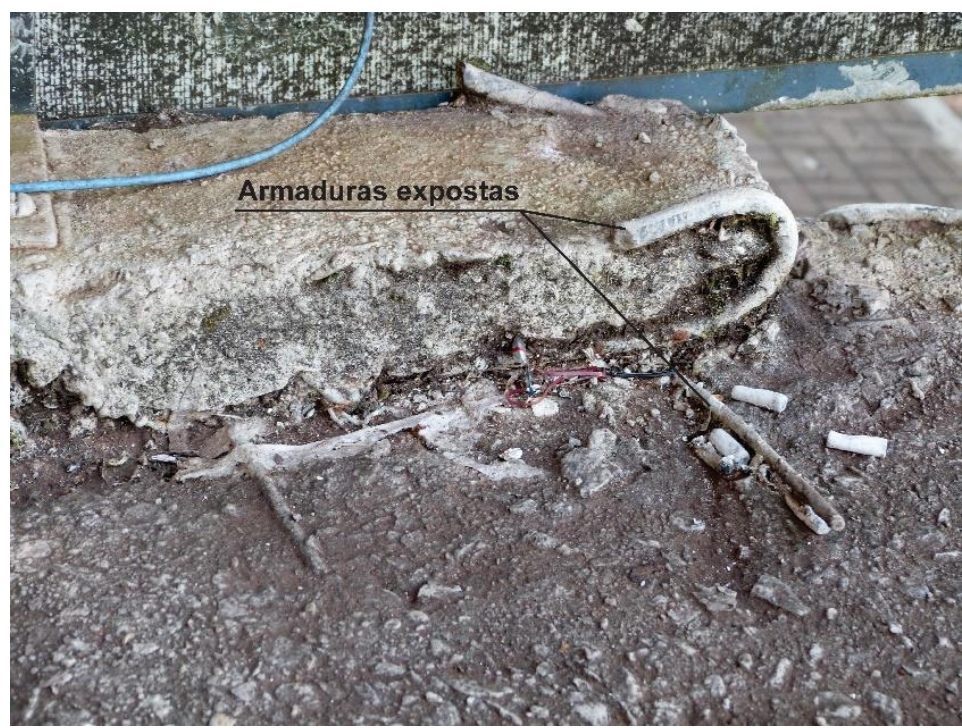

Figura 4: Viga de apoio da marquise M03 (A autora, 2019)

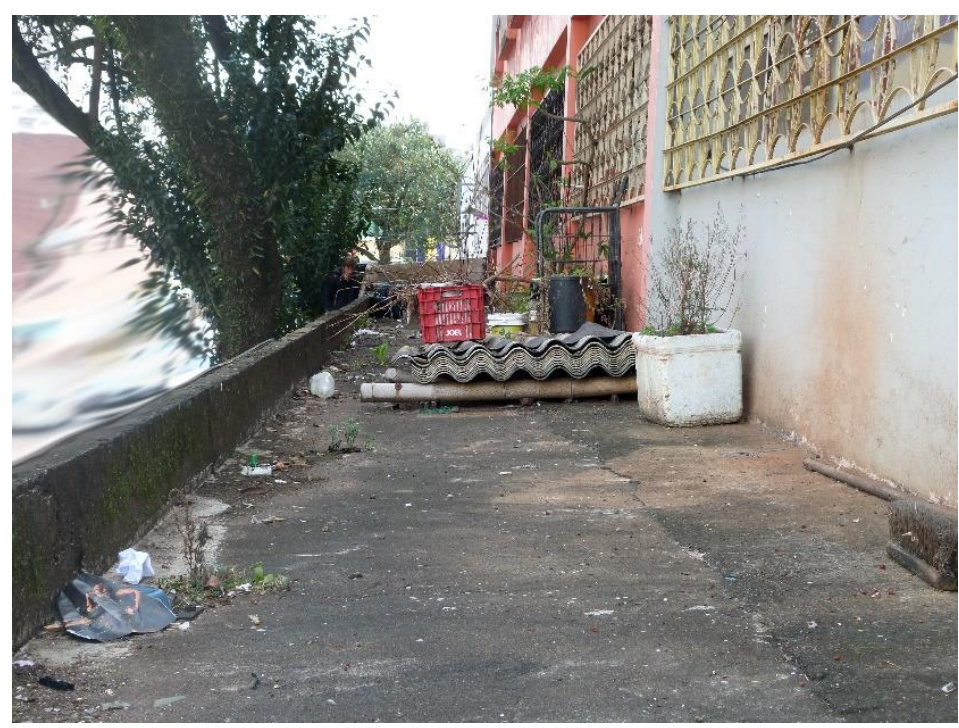

Figura 5: Sobrecarga na marquise M01 (A autora, 2019) 


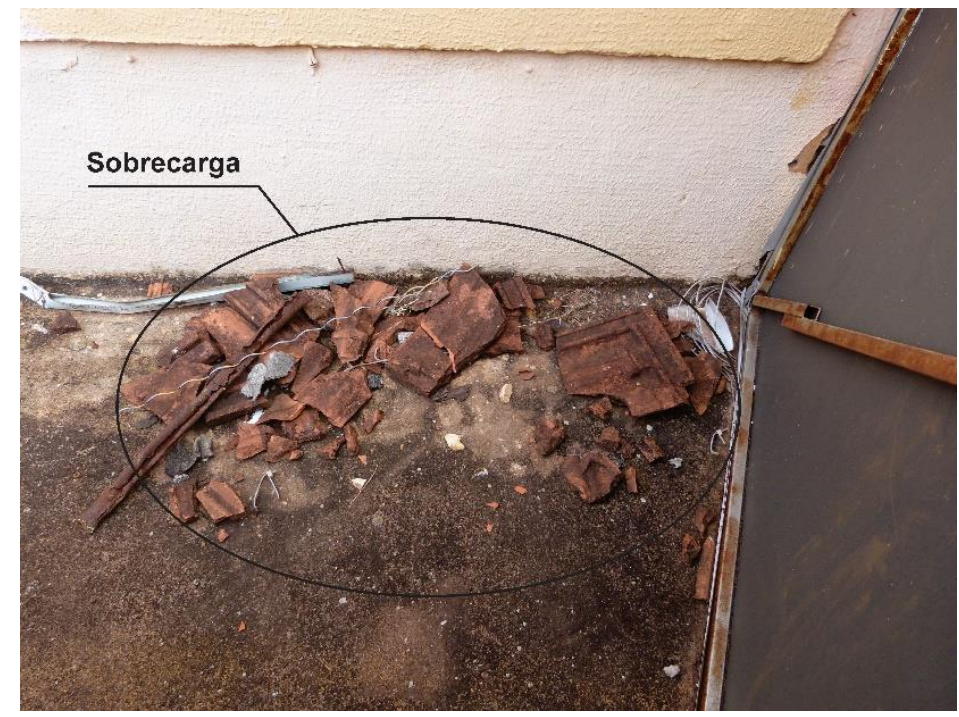

Figura 6: Sobrecarga na marquise M05 (A autora, 2019)

O sétimo item indicado no mesmo gráfico, engloba a presença de vegetações nas marquises. Isto foi verificado principalmente pela vizualização de musgos e pequenas plantas. O oitavo item refere-se a presença de bolores, identificados pela presença de manchas escuras, principalmente nas regiões inferiores das lajes das marquises. Tais manifestações classificam-se como ataque biológico, e estão relacionadas à presença de umidade.

O nono item apresentado no gráfico da Figura 1 refere-se ao acúmulo de detritos e sujeira. Esta presença está associada geralmente a falta de manutenção, e torna-se crítica à medida que pode provocar entupimento do sistema de drenagem, permitindo acúmulo de umidade, que além de causadora de outras manifestações patológicas, pode causar também sobrecarga. As Figuras 7 e 8 apresentam algumas situações de acúmulo de detritos e sujeira observadas.

O décimo item indicado no mesmo gráfico, refere-se ao sistema de drenagem ineficiente. Esta situação foi observada nas quatro marquises da amostra que apresentavam vigas de borda invertidas ou muretas de borda, em função da irregularidade da superfície, que dificulta o escoamento de água a uma direção desejada, e acúmulo de detritos em função da falta de manutenção nas mesmas.

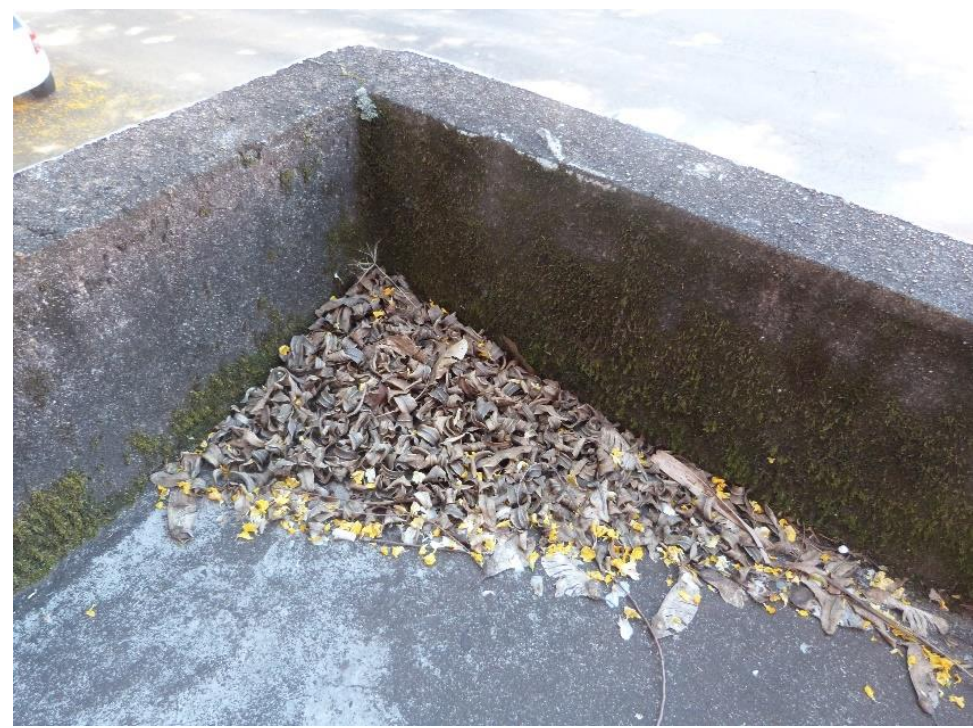

Figura 7: Acúmulo de detritos na marquise M10 (A autora, 2019) 


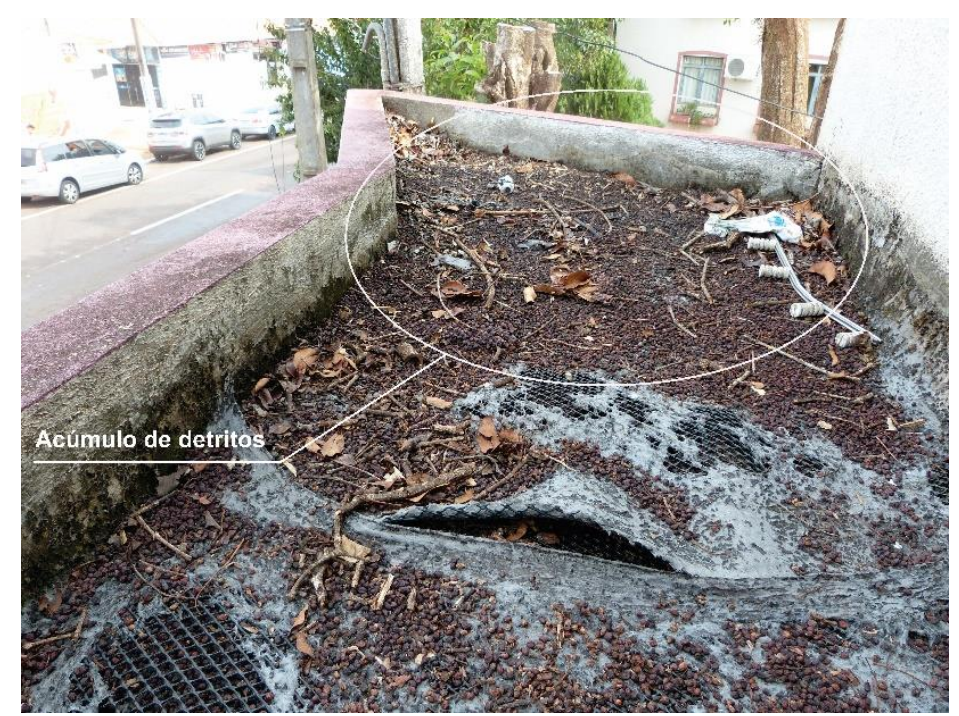

Figura 8: Acúmulo de detritos na marquise M07 (A autora, 2019)

\subsection{Classificação quanto ao grau de deterioração segundo a metodologia GDE/UnB}

Para a apresentação dos resultados, utilizou-se de uma legenda de cores, baseada nas categorias de nível de deterioração apresentadas na Tabela 4. Desta forma, as cores verde, azul, amarelo, laranja e vermelho correspondem às classificações baixo, médio, alto, sofrível e crítico, respectivamente. O gráfico da Figura 9 apresenta os resultados obtidos para o nível de deterioração das marquises inspecionadas com a utilização da metodologia GDE/UnB.

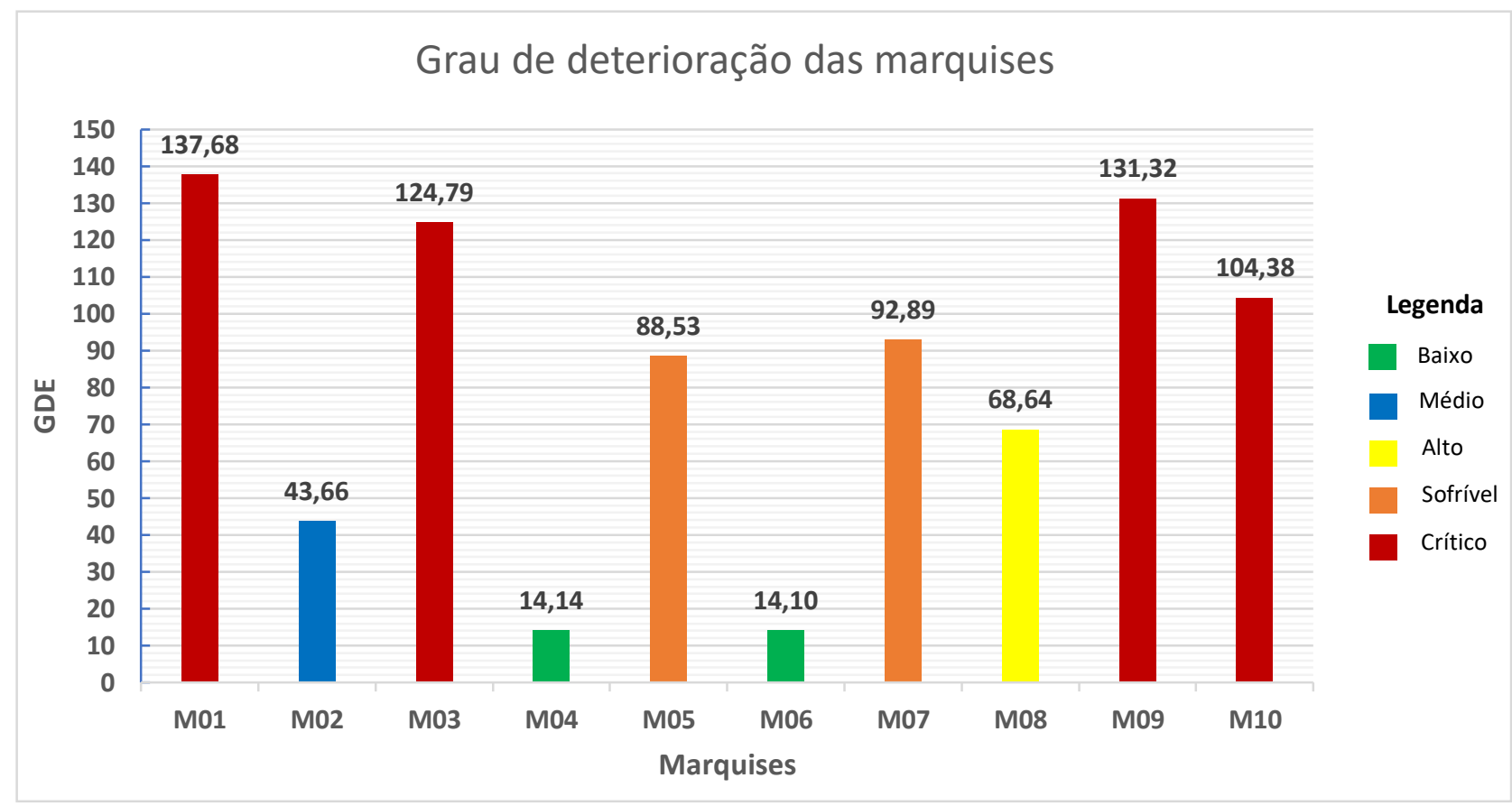

Figura 9: Resultados do grau de deterioração das marquises inspecionadas (A autora, 2019)

\section{CONCLUSÕES}

A partir dos resultados obtidos com a pesquisa, pode-se concluir que há marquises na região central do município de Cascavel que necessitam de atenção imediata, de forma a evitar a ocorrência de acidentes, e esta pode ser a realidade de outras marquises que não foram contempladas neste estudo. 
As quatro marquises que obtiveram classificação do nível de deterioração como crítico, apresentaram armaduras expostas com corrosão. Devido a este fato, seria viável agir preventivamente efetuando reforço estrutural. Em alguns casos, quando possível, poderia se considerar a remoção das mesmas, devido à dificuldade de se realizar um processo de recuperação que garanta a integridade das armaduras, com interrupção do processo de oxidação, além dos custos que seriam demandados para se realizar tais reparos.

Para as marquises que obtiveram classificação como "alto" ou "sofrível”, seria necessária a elaboração de uma proposta de recuperação especializada, visando corrigir os defeitos, quando possível, e minimizar a ação das manifestações patológicas existentes. Além disso, um plano de ação de manutenções preventivas periódicas prolongaria a vida útil do elemento.

Para as demais marquises, classificadas com nível de deterioração "baixo" a "médio", as intervenções em sua maioria seriam de caráter preventivo, de modo a evitar a evolução das manifestações patológicas existentes, que nestes casos ainda não estavam afetando a estrutura propriamente dita.

Pelas observações realizadas, constata-se a falta de conhecimento por parte dos usuários, síndicos e responsáveis pelas edificações, dos riscos envolvidos em relação ao mau uso da estrutura. Em muitos casos, encontraram-se elementos causando sobrecarga, acúmulo de detritos e sujeira sobre as marquises e sistema de drenagem ineficiente. Além disso, os elevados níveis de deterioração encontrados em algumas delas demonstram que estas passavam por pouca ou nenhuma manutenção, e estas quando realizadas, se limitavam a intervenções de caráter estético, como a pintura, muitas vezes ainda, executadas apenas na região inferior da laje.

Os maiores níveis de deterioração foram encontrados em marquises de edificações com idades de aproximadamente 50 anos. Pode-se relacionar este resultado com a ausência de normas que exigissem cobrimentos mínimos de concreto nos elementos estruturais, além da menor qualidade dos concretos utilizados na época, aliado a falhas decorrentes do uso, como a falta de manutenção e sobrecargas.

O fato de os maiores níveis de deterioração terem sido encontrados em marquises de edificações antigas, com aproximadamente 50 anos, não se mostrou como regra, visto que a marquise M10, que possui 34 anos de idade, apresentou também elevados níveis de deterioração.

Com relação a escolha do arranjo estrutural das marquises, não foi possível estabelecer correlações com os níveis de deterioração. Entretanto, constatou-se que as marquises que possuíam vigas ou muretas de borda apresentaram maior incidência de manifestações patológicas relacionadas a umidade, tais quais como ataque biológico, trincas perpendiculares ao plano da fachada na região inferior da laje com sinais de infiltração e eflorescências.

Sendo assim, destaca-se a importância da intervenção do poder público, no sentido de cobrar dos proprietários ou responsáveis pelas edificações, através da criação de legislação específica, exigindo a realização de inspeções periódicas com emissão de laudo por profissional habilitado que garanta a segurança estrutural do elemento marquise, e por conseguinte, garantindo a segurança da população que transita pelo espaço público sob as marquises.

\section{REFERÊNCIAS}

CARMO, M. A. do. Estudo da deterioração de marquises de concreto armado nas cidades de Uberlândia e Bambuí. Pós-Graduação em Engenharia Civil. Dissertação de Mestrado. Universidade Federal de Uberlândia. Uberlândia: 2009. 139 p. Disponível em: <https://repositorio.ufu.br/bitstream/123456789/14131/1/dis.pdf> Acesso em: 11 nov. 2018.

CASTRO, E. K. de. Desenvolvimento de Metodologia para Manutenção de Estruturas de Concreto Armado. Dissertação (Mestrado em Estruturas), Departamento de Engenharia Civil. Universidade de Brasília, Brasília, DF, 1994.

FONSECA, R. P. da. A estrutura do Instituto Central de Ciências: Aspectos históricos, científicos e tecnológicos de projeto, execução, intervenções e propostas de manutenção. Dissertação de Mestrado em Estruturas e Construção Civil, Publicação E.DM - 006 A/07, Departamento de Engenharia Civil e Ambiental, Universidade de Brasília. Brasília, DF. 2007, 213p. 
GOMES, A. M. et al. Proposta de Norma para Inspeção de Marquise. In: XII COBREAP - Congresso Brasileiro de Avaliações e Perícias, 2003, Belo Horizonte. Anais do XII COBREAP - Congresso Brasileiro de Avaliações e Perícias, 2003.

GONÇALVES, M. de O. Marquises de concreto armado da cidade de Viçosa-MG: manifestações patológicas, inspeção e avaliação do grau de deterioração. 2011. 183 f. Dissertação (Mestrado) - Curso de Engenharia Civil, Universidade Federal de Viçosa, Viçosa, 2011.

LOPES, B. A. R. Sistema de manutenção estrutural para grandes estoques de edificações: Estudo para a inclusão do componente Estrutura de Concreto. Dissertação (Mestrado) - Universidade de Brasília, Brasília, DF,1998, 308p.

MEDEIROS, M. H. F. de.; GROCHOSKI, M. Marquises: por que algumas caem? Vol. 12, n 24, p. 10-17. Revista Concreto. São Paulo, 2007. Disponível em: 〈http://coral.ufsm.br/decc/ECC1006/Downloads/Marquises_quedas.pdf〉. Acesso em: 31 out. 2018.

NAKAGUMA, R. Perigo suspenso: Queda de marquises alerta para o risco de projetos. Revista Téchne. São Paulo, 27 Jun. 2006. Suplemento IPT responde p. 14-17.

OLIVEIRA, B. E. Marquises de concreto armado: identificação de manifestações patológicas na estrutura e proposta de soluções. 2013. 86f. Trabalho de Conclusão de Curso (Graduação) - Curso de Engenharia Civil. Universidade Federal do Rio Grande do Sul. Porto Alegre, 2013 Universidade Federal do Rio Grande do Sul. Porto Alegre, 2013.

PERUCK, D. de A.; ZANCAN, E. C. Vistoria de Marquises: Estudo de caso na travessa Henrique Lodetti, Criciúma-SC. 2011. 16 f. TCC (Graduação) - Curso de Engenharia Civil, Universidade do Extremo Sul Catarinense, Criciúma, 2011.

PINTO, J. M.; MONTE, L. M. Sinistros em marquises no distrito federal. 2015. 30 f. Monografia (Graduação) Curso de Engenharia Civil. Universidade Católica de Brasília, Brasília, 2015. Disponível em:

<https://repositorio.ucb.br/jspui/bitstream/10869/5997/5/jackson\%20mendes\%20pinto\%20e\%20laudson\%20meireles\% 20monte.pdf $>$. Acesso em: 28mai. 2019.

RIBEIRO, L. C. P. Análise de manifestações patológicas em marquises de concreto armado em Florianópolis SC. 2014. 103 f. TCC (Graduação) - Curso de Engenharia Civil, Universidade Federal de Santa Catarina, Florianópolis, 2014.

RIZZO, B. E. Marquises: uma abordagem técnica. Rio de Janeiro: CEPD/Defesa Civil do Rio de Janeiro, 2007. Disponível em: <http://www0.rio.rj.gov.br/defesacivil/PDF/marquise_o_que_fazer.pdf>. Acesso em: 29 out. 2018. 